\title{
APPLICATION OF A COMBINED GLOBAL POSITIONING AND HEART RATE MONITORING SYSTEM IN JUMPER HORSES DURING AN OFFICIAL COMPETITION - A PRELIMINARY STUDY
}

\author{
Marilena BAZZANO ${ }^{1}$, Elisabetta GIUdiCE ${ }^{2}$, Maria RIzZo ${ }^{1}$, Fulvio ConGIU ${ }^{1}$, \\ Alessandro ZUMBO ${ }^{1}$, Francesca ARFUSO ${ }^{1}$, Simona Di PIETRO ${ }^{1}$, Daniele BRUSCHETtA ${ }^{3}$ \\ and Giuseppe PICCIONE ${ }^{1 *}$ \\ ${ }^{1}$ Department of Veterinary Sciences, University of Messina, Polo Universitario \\ dell'Annunziata, 98168 Messina, Italy; ${ }^{2}$ Department of Biological and Environmental \\ Sciences, University of Messina, S. Agata-Messina, Italy; ${ }^{3}$ Department of Biomedical \\ Sciences and Morpho-functional Imaging, University of Messina, Messina, Italy
}

(Received 10 September 2015; accepted 4 May 2016)

The aim of this study was to investigate whether a combined global positioning system (GPS)/heart rate (HR) monitoring system is a valuable tool to assess, step by step, the physiological response of HR and its relationship with speed in healthy horses competing in an official show jumping class. Six mares performing a standardised warm-up and jumping course were monitored using a HR/GPS device. Venous blood lactate (BL), assessed before and after exercise, showed a significant increase $(\mathrm{P}=0.0004)$ following the physical effort. One-way analysis of variance (ANOVA) showed significant changes in HR throughout the experimental period. The analysis of HR data recorded during the warm-up jumping stage showed significantly higher HR $(\mathrm{P}=0.001)$ in the recovery period compared to the related jumping phase. Shifting the fence height from $100 \mathrm{~cm}$ to $125 \mathrm{~cm}$ during the warm-up jumps was also found to cause a significant increase $(\mathrm{P}=$ 0.016) in HR. According to these preliminary results, the simultaneous logging of heart rate and speed has the potential to be a reliable and powerful technique for field testing that can help in the monitoring of the horse's response to jumping effort during training and competition.

Key words: Blood lactate, global positioning system, heart rate, horse, physical exercise

Heart rate (HR) measurements during exercise have been extensively studied to assess the fitness level of the athlete, as well as the intensity of the physical effort. A number of researches dealt with the relationship between exercise and HR in sport horses (Clayton, 1991). Exercise tests of equine athletes can be con-

*Corresponding author; E-mail: giuseppe.piccione@unime.it; Phone: +39 (090) 350-3584; Fax: +39 (090) 350-3975 
ducted in a treadmill laboratory or in the field. The treadmill test allows controlling the physical environment as well as the speed and duration of the exercise but it differs from real exercise conditions. Field tests are difficult to standardise but reproduce the real environment in which horses usually exercise and compete (Hinchcliff et al., 2008). The advantage of field testing over the use of treadmill is better rendered in equestrian disciplines than in racing disciplines (Sloet van Oldruitenborgh-Oosterbaan and Clayton, 1999). Most researches on field exercise testing investigated the responses of body systems to physical exercise in Standardbred trotters (Couroucé, 1999; Couroucé et al., 2002) and Thoroughbred horses (Piccione et al., 2004; Gramkow and Evans, 2006; Evans, 2007). Therefore, cardiovascular, respiratory, metabolic responses and musculoskeletal adaptations to exercise have been well studied, allowing specific exercise testing for racehorses (Hodgson et al., 2014). However, few studies have dealt with exercise testing for event (Munsters et al., 2014), dressage (Williams et al., 2009) and jumper horses (Munk et al., 2013), and little information is available on training effects and fitness assessment for Warmblood sport horses (Munsters et al., 2013). Animals competing in equestrian disciplines are required to have high technical skills and, particularly in show jumping, higher HR values do not necessarily coincide with higher speeds (Clayton, 1989; Art et al., 1990). Therefore, the assessment of intensity, speed and duration during the incremental exercise tests on track, typically used in racehorses, may be improper for evaluating fitness and technical skills of jumper horses. Recent studies (Williams et al., 2009; Mirian and Fernandes, 2011; Munsters et al., 2014) have focused on the evaluation of jumping techniques and the level of fatigue in jumper horses. Alternative methods for assessing the fitness level consist of single-step exercise tests and the monitoring of blood lactate (BL) following exercise, reflecting changes in fitness over time (Davie and Evans, 2000). Overall, a field exercise test typically consists of several incremental bouts of exercise during which HR, BL and speed are assessed (Couroucé et al., 2002; Piccione et al., 2010, 2013). Over the past few years, the development of sensors and sensing techniques has provided new tools to assess horse athletic performance in real time (Aerts et al., 2008). In particular, devices using the global positioning system (GPS) technology in conjunction with a heart rate monitoring system allowed recording simultaneously changes in speed and heart rate following each incremental exercise in Thoroughbreds (Kingston et al., 2006; Vermeulen and Evans, 2006) and Standardbreds (Giosmin et al., 2009). Although show jumping is part of the Olympic equestrian disciplines, and despite the need to monitor fitness and workload, there is a paucity of information about field exercise testing in jumper horses during official competitions (Art et al., 1990; Lekeux et al., 1991; Aguilera-Tejero et al., 2000), and none of these tests used the GPS technology.

Because of the importance of understanding the dynamics of HR during exercise for assessing the performance level in jumping horses, the aim of this 
preliminary study was to evaluate whether a combined GPS/HR monitoring system is a valuable tool to assess, step by step, the physiological response of HR and its relationship with speed in high-level jumper horses performing the same standardised warm-up and jumping course during an official competition.

\section{Materials and methods}

All treatments, housing and animal care reported below were carried out in accordance with the standards recommended by Directive 2010/63/EU on the protection of animals used for scientific purposes.

\section{Animals and study design}

Six clinically healthy and regularly trained Italian Saddlebred mares (mean age $7.6 \pm 0.5$ years; mean body weight $437 \pm 15 \mathrm{~kg}$ ) were used with the informed consent of the owners. Animals were stabled in individual boxes $(3.5 \times$ $3.5 \mathrm{~m})$ at the same training centre in Sicily under natural photoperiod during Spring 2014 (sunrise at 05.00 AM, sunset at 07.00 PM; mean temperature $23{ }^{\circ} \mathrm{C}$, relative humidity $70 \%$ ). All horses are trained and ridden by the same trainer and rider, respectively. Horses were fed, twice a day (07.00 AM; 05.00 PM), a total food amount of about $2.5 \%$ dry-matter of horse body weight (forage:concentrate ratio, 70:30) and water was available ad libitum.

The horses competed in an outdoor national jumper class C135 [according to the Federazione Italiana Sport Equestri (FISE) rules] in the afternoon (12.00 AM - 01.00 PM). The warm-up on the flat was standardized as follows: walk 1 (1 min), trot (3 min), walk $2(1 \mathrm{~min})$, canter $(2 \mathrm{~min})$ and walk 3 (1 min). The next stage of the standardized warm-up included 8 jumps (4 vertical and 4 oxers) of increasing height $(100 \mathrm{~cm}, 115 \mathrm{~cm}, 125 \mathrm{~cm}, 135 \mathrm{~cm})$. Each warm-up jump was made up of a jumping phase proper including the approach (at canter) and the passing of the jump, followed by a short recovery period $(20 \mathrm{sec})$ at walk. The trainer timed each warm-up stage and used the same sequence of jumps (alternating verticals and oxers with the same height) for all subjects. After the warm-up, horses competed in the same jumping course with the following technical specifications: total length: $500 \mathrm{~m}$; time limit: $172 \mathrm{sec}$; obstacles height: $135 \mathrm{~cm}$; total efforts: 15 (9 verticals, 6 oxers, 1 double and 1 triple combinations). The competition stage was made up of four phases including: inbound (waiting time inside the arena before competing), course (time of the jumping phase), outbound (time lapse between the end of the course and the exit from the arena), end (time lapse between the exit and the arrival to the stable).

Along the experimental period, video recordings (HFR506, Canon, Tokyo, Japan) were performed for each horse in order to share exactly every stage in the experimental period. 


\section{Measuring devices}

Heart rate and speed. Prior to exercise, at rest in the stall, horses and riders were fitted with the Forerunner $305^{\circledR}$ combined HR and GPS monitoring system (Garmin, Kansas, USA). The heart rate electrodes were placed under the girth and saddle on the left side; the horses' skin was previously shaved and moistened with water to improve the conductivity of the electrical signals between the skin and the electrodes (Fig. 1). The riders wore a watch containing a GPS receiver that displayed and recorded the horse's HR and GPS signal. The HR/GPS monitoring system had a continuous sample rate $(1 / \mathrm{sec})$ and a speed accuracy $<0.05 \mathrm{~m} / \mathrm{sec}$. The GPS/HR monitoring system used in this study was previously used and validated in equine species (Giosmin et al., 2009). The recorded HR and GPS data were downloaded using the Garmin Training Center Software and converted into data files containing time, distance, speed, and HR for each data point.
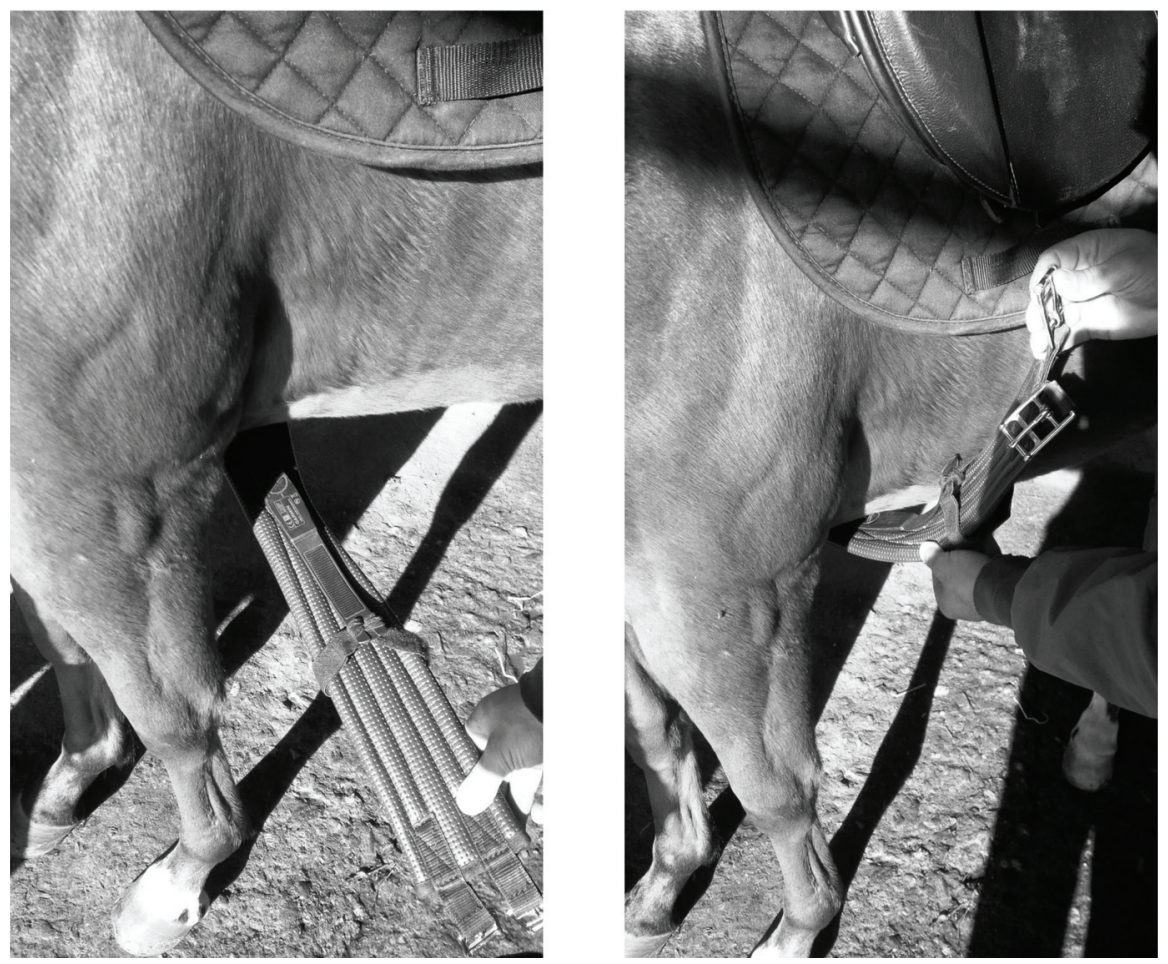

Fig. 1. Set-up of the GPS/HR monitoring system on horses

Venous blood lactate. In order to assess BL concentrations, all horses were subjected to blood sampling at rest in the stall and $5 \mathrm{~min}( \pm 10 \mathrm{sec})$ following cessation of the exercise. The samples were collected by jugular venipuncture 
into EDTA vacutainer test tubes in order to assess blood lactate (BL) using the Accusport ${ }^{\circledR}$ portable blood lactate analyser (Boehringer, Germany), immediately after sample collection.

\section{Statistical analysis}

The obtained values were tested for normality using the KolmogorovSmirnov test. A paired $t$-test was applied to compare BL levels recorded at rest and after the physical effort. One-way repeated-measures analysis of variance (ANOVA) was applied to study the influence of each step of the warm-up (walk, trot, canter, jumps 1-8) and competition (inbound, course, outbound, end) on HR. When statistical significances $(\mathrm{P}<0.05)$ were found, Tukey's post-hoc comparison test was applied. The Pearson correlation test was applied to investigate the relationship between HR and speed in warm-up (walk, trot, canter and jumps) and competition phases (inbound, course, outbound and end). Furthermore, two-way ANOVA was used to assess the influence of obstacle height on HR values, and to compare HR recordings during each jumping phase and the related recovery period of the 8 warm-up jumps. All data were analysed using the PRISM 6 statistical software (GraphPad Software Inc., La Jolla, California).

\section{Results}

The horses included in the study completed the jumping course within the time limit and without penalties, ranking within the first 10 positions. $0.05)$.

The obtained data passed the Kolmogorov-Smirnov normality test $(\mathrm{P}>$

Table 1 shows the duration and the mean values of HR and speed recorded for each horse during each phase of the competition. Statistical analysis showed a significant increase $(\mathrm{P}=0.0004)$ in $\mathrm{BL}$ levels after the physical effort $(4.6 \pm$ $1.1 \mathrm{mmol} / \mathrm{l})$ compared to the resting values $(1.5 \pm 0.4 \mathrm{mmol} / \mathrm{l})$. One-way repeated-measures ANOVA showed significant changes in HR throughout the experimental period, with the highest HR values recorded during the course and at the end of competition (Fig. 2). The representative trend of HR and speed recorded in horses throughout the monitoring period is shown in Fig. 3. Table 2 shows the results of Pearson correlation analysis throughout the monitoring period. In particular, during the warm-up phases a significant negative correlation was found between HR and speed values in walk phase; HR values were positively correlated with speed in trot phase, whereas no significant correlation was found between HR and speed values in canter and jump phases. During the competition phases a significant negative correlation was found between HR and speed values in the inbound phase, whereas HR values were positively correlated with speed in the course, outbound and end phases. 


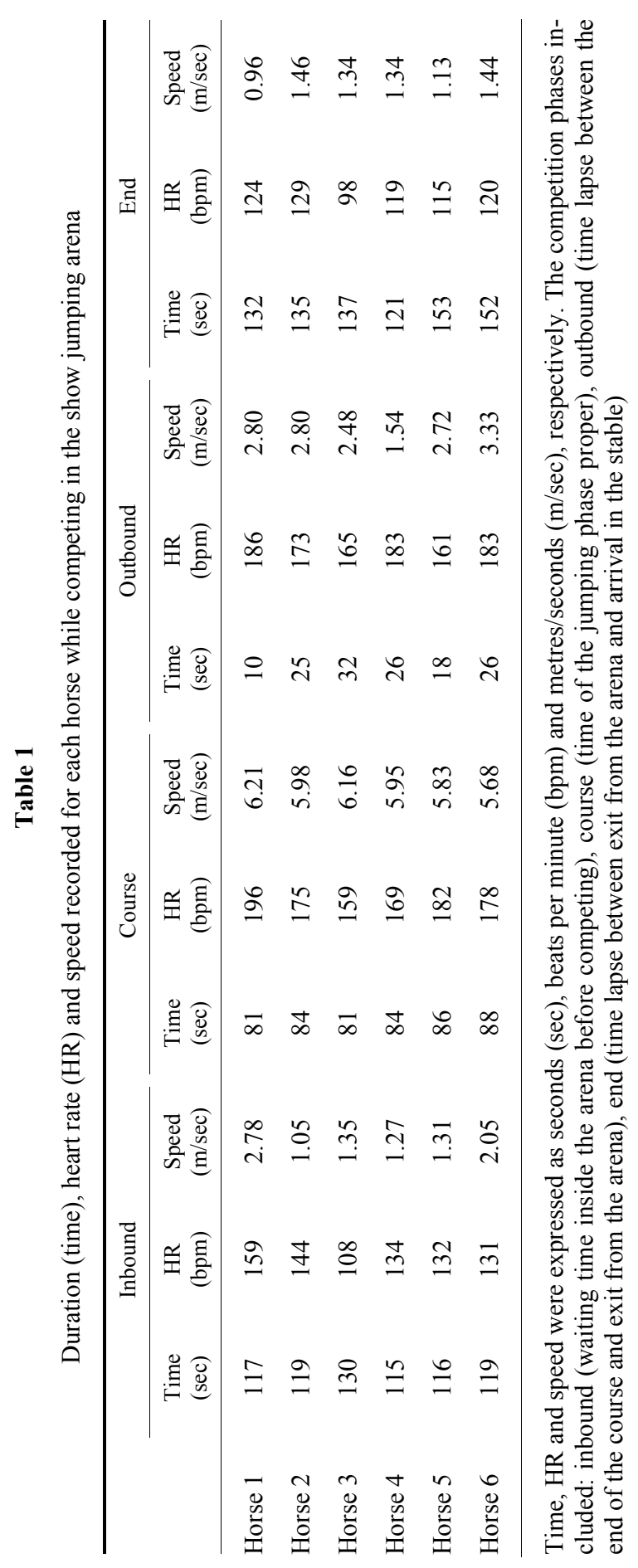




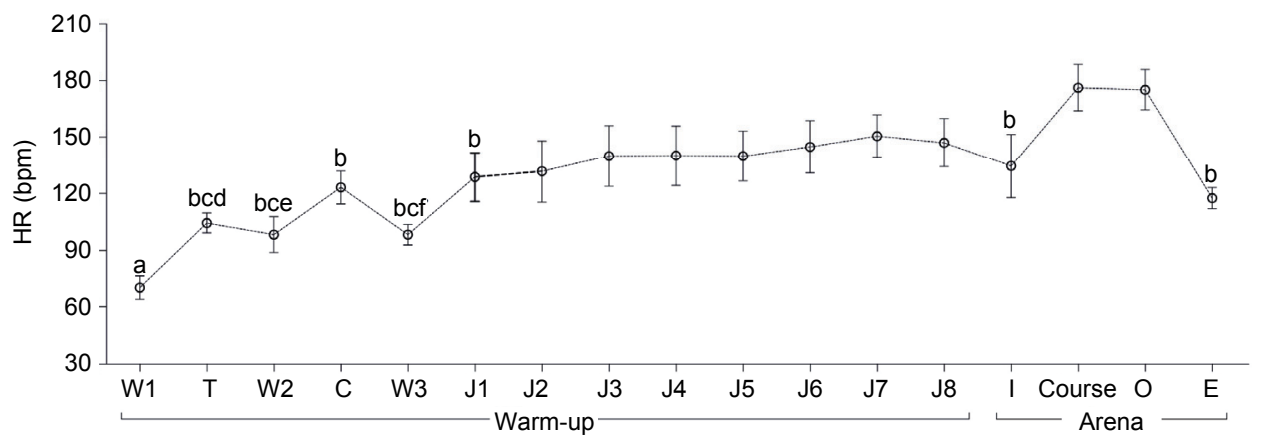

Fig. 2. Heart rate (HR) values recorded during the experimental period are expressed as beats per minute (bpm). The warm-up on the flat included walk (W1-W3), trot (T) and canter (C) sections, followed by 8 warm-up jumps (J1-J8). The competition in the show jumping arena was divided into four stages including inbound (I), course, outbound (O), and end (E). The letters on the top of the data point indicate the following statistical significances: a: vs. all data points; b: vs. course and outbound; c: vs. canter; d: vs. jump 5 to 8 ; e: vs. jump 1 to 8 ; f: vs. jump 3 to 8

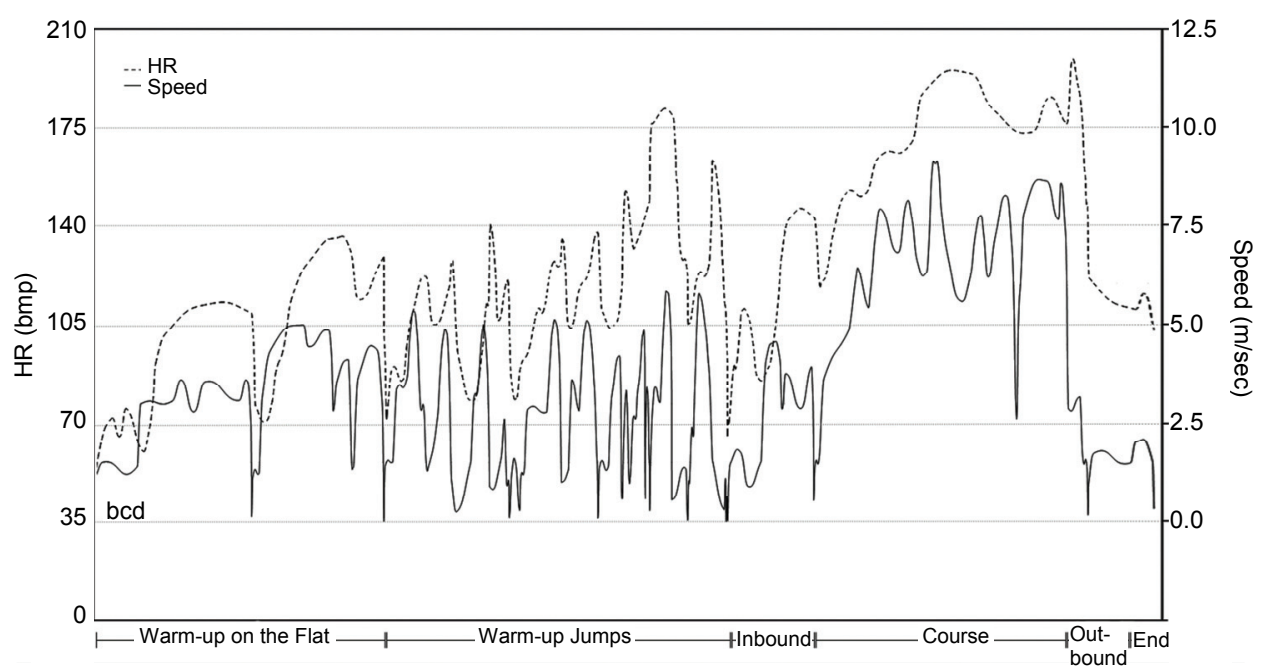

Fig. 3. Heart rate (HR) and speed graphs recorded using the Garmin Forerunner $305^{\circledR} \mathrm{GPS} / \mathrm{HR}$ monitoring system. On the $x$-axis the main stages of the experimental period are indicated

The statistical analysis of HR data recorded during the jumping stage of the warm-up showed significantly higher HR $(\mathrm{P}=0.0011)$ in the recovery period compared to the related jumping phase. The fence height was also found to cause a significant increase $(\mathrm{P}=0.0158)$ in $\mathrm{HR}$ when shifting from $100 \mathrm{~cm}$ to $125 \mathrm{~cm}$ jumps (J1 and J2 vs. J6-J8) in the warm-up stage (Fig. 4). 
Table 2

Coefficients of correlation between heart rate and speed calculated in six jumper horses during warm-up (walk, trot, canter and jumps) and competition phases (inbound, course, outbound and end)

\begin{tabular}{|c|c|c|c|c|}
\hline \multirow{2}{*}{ Speed $(\mathrm{m} / \mathrm{sec})$} & \multicolumn{4}{|c|}{ Heart rate (bpm) } \\
\hline & Walk & Trot & Canter & Jumps \\
\hline Walk & $\begin{array}{l}r=-0.65 \\
P<0.001\end{array}$ & & & \\
\hline Trot & & $\begin{array}{c}r=0.58 \\
P<0.001\end{array}$ & & \\
\hline Canter & & & $\begin{array}{l}r=-0.12 \\
P=0.25\end{array}$ & \\
\hline \multirow[t]{2}{*}{ Jumps } & & & & $\begin{array}{l}r=0.09 \\
P=0.24\end{array}$ \\
\hline & Inbound & Course & Outbound & End \\
\hline Inbound & $\begin{array}{c}r=-0.53 \\
P=0.03\end{array}$ & & & \\
\hline Course & & $\begin{array}{c}r=0.55 \\
P<0.001\end{array}$ & & \\
\hline Outbound & & & $\begin{array}{c}r=0.76 \\
P<0.001\end{array}$ & \\
\hline End & & & & $\begin{array}{l}r=0.22 \\
P=0.01\end{array}$ \\
\hline
\end{tabular}

Significant correlations $(\mathrm{P}<0.05)$ are indicated in bold letters

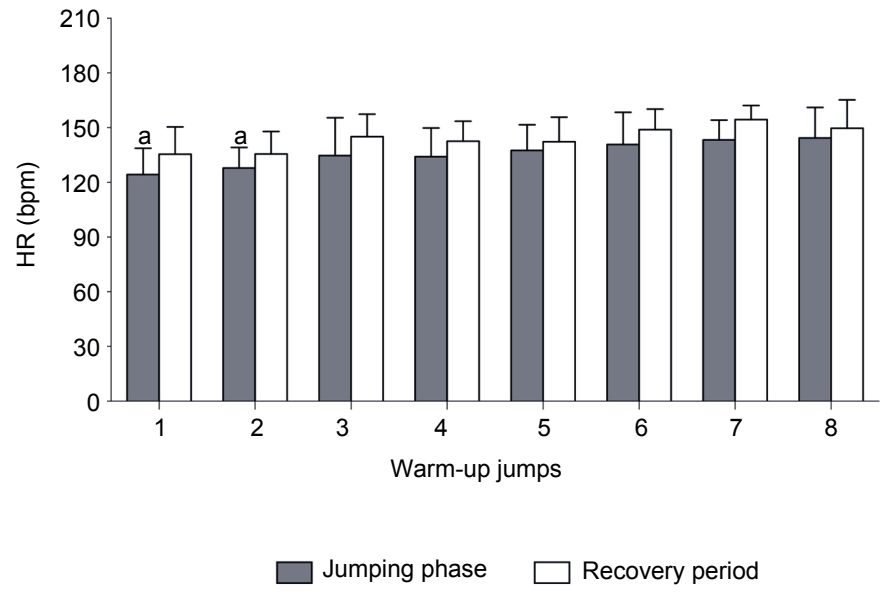

Fig. 4. Heart rate (HR) expressed as beats per minute (bpm) during the jumping stage of the warmup. A significantly higher HR was observed in the recovery period (white columns) compared to the related jumping phase (grey columns). The letter ' $a$ ' on the top of the columns indicates a statistically significant difference vs. jump 6 to 8 


\section{Discussion}

In the present study, we found significant changes in the main indices of horses' fitness during both the warm-up stage and the jumping course of a national jumping class.

After completing the exercise, venous BL concentrations increased by about 3 -fold compared to rest. Other authors investigating horse performance during official jumping competitions obtained similar results (Art et al., 1990; Lekeux et al., 1991) but reported higher BL levels post-exercise than ours. The difference in BL levels might result from a number of variables such as obstacle height, duration of the exercise, fitness of horses included in the studies as well as the blood sampling time. It takes about 30 min to clear lactic acid from the muscles and bloodstream after exercise (Loving and Johnston, 1995). Within a few minutes, the lactate levels start to decrease because removal from the circulation exceeds the rate of release from the muscles (Clayton, 1991). Despite this, our results confirm the significant contribution of anaerobic metabolism during jumping exercise (Hodgson et al., 2014). During the study, significant changes were observed in HR with the highest values reached during and immediately after the jumping course (mean HR: $176 \pm 12 \mathrm{bpm}$ ). The official competition itself probably represented a contributing factor to HR increase, as mental stress (Rietmann et al., 2004) and emotionality (Visser et al., 2002; Jansen et al., 2009) might play a role in affecting HR during the course. Effectively, the use of the GPS/HR monitoring system allowed us to simultaneously record the horses' HR and speed changes, showing high HR values despite a low mean speed during the inbound to the show jumping arena before competing. This finding is in line with the hypothesis that an increase in HR is not only caused by an increase in physical activity, but also reflects heightened emotional reactivity (Jansen et al., 2009). Therefore, HR may indicate the animal's internal physiological state, as well (Jansen et al., 2009). Similar HR trends have been previously observed by Lekeux et al. (1991) in Belgian Saddlebreds competing in the Belgian Championship. In that study, the authors suggested the onset of fatigue and the need for accelerating near the finish as causes for HR increase. The relationship between speed and heart rate has been extensively investigated in treadmill and field exercise testing (Hodgson et al., 2014). The results obtained in the present study highlighted that during warm-up, HR and speed values were negatively correlated in walk and positively correlated in trot, whereas a lack of correlation was found between these parameters in the canter and jumps phases. The lack of correlation between HR and speed values is probably due to the workload of the previous phases, thus HR values continue to be high even if the speed decreases. During the competition phases, HR negatively correlated with speed in the inbound phase. This finding highlighted the increased emotional reactivity of athletes occurring before the show jumping competition (Jansen et al., 2009). During the course, outbound and end phases the HR values were positively correlated 
with speed. In conformity with our results, a good correlation $(\mathrm{r}=0.75)$ was previously found between HR and speed in Thoroughbreds (Hodgson et al., 2014). All horses reached the highest speed during the course competing at a mean speed of 6 $\mathrm{m} / \mathrm{s}$; however, the relationship between HR and speed during show jumping was not as strong as in racehorses. In the authors' opinion, this gap might be due to the jumping effort causing an increase in HR irrespective of speed during the jumping phase. In the present study, particular attention was paid to analysing HR changes during the standardised warm-up. The support of video recordings allowed us to relate changes in HR to specific stages of the warm-up such as the moment of jump and the related recovery period. The obstacle height caused a significant increase in the horses' HR when shifting from $100 \mathrm{~cm}$ to $125 \mathrm{~cm}$. This increase in HR might be due to the sympathetic nervous activity that increases with increasing exercise intensity. This results in a consistent increase in catecholamine levels enhancing the increase in heart rate, the force of cardiac contraction and thus the cardiac output (McKeever and Gordon, 2004). Focusing on the warm-up jumping phase, HR tended to increase in the recovery period compared to the execution of the related jump. This unexpected finding might result from the release of catecholamines following the physical effort of jumping. Effectively, the plasma halflife of these hormones is around $30 \mathrm{sec}$ and the recovery periods in our study lasted about $20 \mathrm{sec}$ (Hyyppä, 2005); probably this is the reason for the higher HR observed during the recovery periods of the warm-up jumping phase.

To the best of the authors' knowledge, this is the first study investigating some fitness indices in horses competing in official jumping class by means of a combined HR/GPS monitoring system. According to the results of this preliminary study, the simultaneous logging of heart rate and speed from each horse proved to be a reliable and powerful technique for field testing that can help in monitoring, step by step, the horse's response to the jumping effort during both training and competition. This could ensure that horses receive a suitable training load for their ability and potentially minimise the risk of injury. Matching up horses of similar ability or fitness may allow for a more balanced training approach. It could also help eliminate training sessions that fail to provide a sufficient training stimulus. Moreover, this approach might allow us to quantify objectively how a horse is coping with its training exercises or the emotional stress of a competition and to assess the degree of compliance of the horse that will in turn contribute to improving animal welfare and athletic performance.

\section{Acknowledgements}

The authors wish to thank the New Eagle's equestrian training center (Catania, Italy) for providing horses and riders, and the trainer Mr. Ciro Carrabotta for collaborating during the study. 


\section{References}

Aerts, J. M., Gebruers, F., Van Camp, E. and Berckmans, D. (2008): Controlling horse heart rate as a basis for training improvement. Comput. Electron. Agr. 64, 78-84.

Aguilera-Tejero, E., Estepa, J. C., López, I., Bas, S., Mayer-Valor, R. and Rodriguez, M. (2000): Quantitative analysis of acid-base balance in show jumpers before and after exercise. Res. Vet. Sci. 68, 103-108.

Art, T., Amory, H., Desmecht, D. and Lekeux, P. (1990): Effect of show jumping on heart rate, blood lactate and other plasma biochemical values. Equine Vet. J. Suppl. 9, 78-82.

Clayton, H. M. (1989): Time-motion analysis in equestrian sports: The Grand Prix dressage test. In: Proceedings of the 35th Annual Convention of the American Association of Equine Practitioners, Boston. pp. 367-373.

Clayton, H. M. (1991): Conditioning Sport Horses. Sport Horse Publications, Saskatchewan.

Couroucé, A. (1999): Field exercise testing for assessing fitness in French Standardbred trotters. Vet. J. 157, 112-122.

Couroucé, A., Chretien, M. and Valette, J. P. (2002): Physiological variables measured under field conditions according to age and state of training in French Trotters. Equine Vet. J. 34, 91-97.

Davie, A. J. and Evans, D. L. (2000): Blood lactate responses to submaximal field exercise tests in thoroughbred horses. Vet. J. 159, 252-258.

Evans, D. L. (2007): Physiology of equine performance and associated tests of function. Equine Vet. J. 39, 373-383.

Giosmin, L., Lagas, E., Bailoni, L. and Mantovani, R. (2009): Use of GPS technique to measure length and intensity of physical activity in trotting horses during outdoor training. In: Proceeding in Nuove acquisizioni in materia di Ippologia. Druento (TO), pp. 62-66.

Gramkow, H. L. and Evans, D. L. (2006): Correlation of race earnings with velocity at maximal heart rate during a field exercise test in Thoroughbred racehorses. Equine Vet. J. Suppl. 36, $118-122$.

Hinchcliff, K. W., Geor, R. J. and Kaneps, A. J. (2008): Equine Exercise Physiology. Saunders Elsevier, Edinburgh.

Hodgson, D. R., McGowan, C. and McKeever, K. (2014): The Athletic Horse: Principles and Practice of Equine Sports Medicine. Second edition. Saunders Elsevier, St. Louis.

Hyyppä, S. (2005): Endocrinal responses in exercising horses. Livest. Prod. Sci. 92, 113-121.

Jansen, F., Van der Krogt, J., Van Loon, K., Avezzù, V., Guarino, M., Quanten, S. and Berckmans, D. (2009): Online detection of an emotional response of a horse during physical activity. Vet. J. 181, 38-42.

Kingston, J. K., Soppet, G. M., Rogers, C. W. and Firth, E. C. (2006): Use of a global positioning and heart rate monitoring system to assess training load in a group of thoroughbred racehorses. Equine Vet. J. Suppl. 35, 106-109.

Lekeux, P., Art, T., Linden, A., Desmecht, D. and Amory, H. (1991): Heart rate, haematological and serum biochemical responses to show jumping. In: Persson, S. G. B., Lindholm, A. and Jeffcott, L. B. (eds) Equine Exercise Physiology. ICEEP Publications, Davis, CA. pp. 385-390.

Loving, N. S. and Johnston, A. M. (1995): Veterinary Manual for the Performance Horse. Blackwell Science Ltd., Oxford, London.

McKeever, K. H. and Gordon, M. B. (2004): Endocrine alterations in the equine athlete. In: Hinchcliff, K. W., Geor, R. J. and Kaneps, A. J. (eds) Equine Sport Medicine and Surgery. Elsevier Saunders, Edinburgh. pp. 793-814.

Mirian, M. and Fernandes, W. R. (2011): Padronização de teste incremental de esforço máximo a campo para cavalos que pratiquem hipismo clássico. Vet. Zootec. 18, 668-679.

Munk, R., Møller, S. and Lindner, A. (2013): Effects of training with different interval exercises on horses used for show jumping. Comp. Exercise Physiol. 9, 33-41. 
Munsters, C. C., van Iwaarden, A., van Weeren, R. and Sloet van Oldruitenborgh-Oosterbaan, M. M. (2014): Exercise testing in Warmblood sport horses under field conditions. Vet. J. 202, $11-19$.

Munsters, C. C. B. M., van den Broek, J., Welling, E., van Weeren, R. and Sloet van OldruitenborghOosterbaan, M. M. (2013): Prospective study of a cohort of horses and ponies selected for participation in the European Eventing Championship: Reasons for withdrawal and predictive value of fitness tests. BMC Vet. Res. 9, 182.

Piccione, G., Assenza, A., Fazio, F., Percipalle, M. and Caola, G. (2004): Assessment of anaerobic threshold in the galloper using a standardised exercise field test. Vet. Med. 49, 291-297.

Piccione, G., Messina, V., Bazzano, M., Giannetto, C. and Fazio, F. (2013): Heart rate, net cost of transport, and metabolic power in horse subjected to different physical exercises. J. Equine Vet. Sci. 33, 386-389.

Piccione, G., Messina, V., Casella, S., Giannetto, C. and Caola, G. (2010): Blood lactate levels during exercise in athletic horses. Comp. Clin. Pathol. 19, 535-553.

Rietmann, T. R., Stuart, A. E. A., Bernasconi, P., Stauffacher, M., Auer, J. A. and Weishaupt, M. A. (2004): Assessment of mental stress in warmblood horses: heart rate variability in comparison to heart rate and selected behavioural parameters. Appl. Anim. Behav. Sci. 88, $121-136$.

Sloet van Oldruitenborgh-Oosterbaan, M. M. and Clayton, H. M. (1999): Advantages and disadvantages of track tests versus treadmill tests. Equine Vet. J. Suppl. 30, 645-648.

Vermeulen, A. D. and Evans, D. L. (2006): Measurements of fitness in Thoroughbred racehorses using field studies of heart rate and velocity with a global positioning system. Equine Vet. J. Suppl. 36, 113-117.

Visser, E. K., Van Reenen, C. G., Van Der Werf, J. T. N., Schilder, M. B. H., Knaap, J. H., Barneveld, A. and Blokhuis, H. J. (2002): Heart rate and heart rate variability during a novel object test and a handling test in young horses. Physiol. Behav. 76, 289-296.

Williams, R. J., Chandler, R. E. and Marlin, D. J. (2009): Heart rate of horses during competitive dressage. Comp. Exercise Physiol. 6, 7-15. 